УДК 635.0.813

\title{
СОСТАВ ЭКСТРАКТОВ ДРЕВЕСНОЙ ЗЕЛЕНИ JUNIPERUS SIBIRICA BURGSD
}

\author{
(ㄷ) Е.В. Матвеенко", Е.Н. Аёиина, Н.А. Величко \\ Сибирский государственный технологический университет, пр. Мира, 82, \\ Красноярск, 660049 (Россия), e-mail: vollker@mail.ru
}

\begin{abstract}
Проведено исследование влияния природы растворителя на выход биологически активных веществ из древесной зелени Juniperus sibirica B. Установлено, что наибольший выход биологически активных веществ из древесной зелени Juniperus sibirica наблюдается при использовании 45\%-го раствора этилового спирта. Рассмотрено влияние условий хранения на выход экстрактивных веществ.

Ключевые слова: экстракт, биологически активные вещества, Juniperus sibirica B.
\end{abstract}

\section{Введение}

Можжевельник как лекарственное растение используется в народной медицине в виде отваров, настоев и вытяжек. Экстракты, настои из древесной зелени можжевельника обыкновенного широко применяются в медицине, парфюмерной и пищевой промышленности. Древесная зелень можжевельника является источником ценных биологически активных веществ. Использование биологически активных веществ в виде натуральных ингредиентов, разнообразных композиций вызывает несомненный интерес во всем мире. Можжевельник выделяет в 6 раз больше ароматических веществ, губительно действующих на бактерии, чем сосна [1]. Согласно литературным данным, извлекают биологически активные вещества из древесной зелени экстракцией, настаиванием. В состав экстрактивных веществ входит большое число полезных соединений [2].

Объектом исследования служила древесная зелень можжевельника сибирского (Juniperus sibirica B.).

Цель исследования - поиск условий и экстрагента для обеспечения наибольшего выхода экстрактивных веществ из древесной зелени можжевельника сибирского.

\section{Экспериментальная часть}

Исходным сырьем была свежая древесная зелень Juniperus sibirica $B$, произрастающего на территории Партизанского района Красноярского края. Образцы были собраны с 10-20 кустарников, усреднялись методом квартования. Содержание биологически активных веществ в экстрактах определялось по методикам, принятым в химии и биохимии растений [3-7].

Экстракцию древесной зелени Juniperus sibirica B. проводили водой и раствором этилового спирта. Кон-

Матвеенко Егор Владимирович - аспирант кафедры химической технологии древесины и биотехнологии, e-mail: vollker@mail

Аёшина Екатерина Николаевна - доцент кафедры химической технологии древесины и биотехнологии, кандидат технических наук

Величко Надежда Александровна - профессор кафедры химической технологии древесины и биотехнологии, доктор технических наук центрация этилового спирта выбрана 45\% на основании предварительно проведенных экспериментов [8-10].

Экстракцию проводили при температуре кипения экстрагента и атмосферном давлении 736-738 мм рт. ст. в течение 150 мин [8]. Выход биологически активных веществ из древесной зелени можжевельника сибирского при экстракции водой и 45\%-м раствором этилового спирта приведен в таблице.

\footnotetext{
* Автор, с которым следует вести переписку.
} 
Выход биологически активных веществ из древесной зелени Juniperus sibirica B.

\begin{tabular}{|c|c|c|}
\hline \multirow[t]{3}{*}{ Компоненты } & \multicolumn{2}{|c|}{ Экстрагент } \\
\hline & вода & 45\%-й раствор этанола \\
\hline & \multicolumn{2}{|c|}{ Содержание, мг\% } \\
\hline Витамин C & $159 \pm 2$ & $1273,19 \pm 2$ \\
\hline Витамин Р & $8,86 \pm 2$ & $24,12 \pm 2$ \\
\hline Хлорофилл А & $1,03 \pm 0,1$ & $1,20 \pm 0,1$ \\
\hline Хлорофилл В & $2,25 \pm 0,1$ & $2,72 \pm 0,1$ \\
\hline Каротин & $0,86 \pm 0,1$ & $0,18 \pm 0,1$ \\
\hline Флавоноиды & $1080,24 \pm 2$ & $3355,14 \pm 2$ \\
\hline
\end{tabular}

\section{Обсуждение результатов}

Как видно из результатов, приведенных в таблице, обращает на себя внимание высокое содержание витамина С в водно-спиртовом экстракте древесной зелени Juniperus sibirica, которое на 87,60\% выше, чем в водном.

Степень извлечения флавоноидов 45\%-м водно-спиртовым раствором этилового спирта на 67,80\% выше, чем при экстрагировании водой.

Таким образом, применение 45\%-го раствора этилового спирта при экстрагировании можжевельника сибирского обеспечивает наибольший выход биологически активных веществ.

Рассмотрено влияние продолжительности хранения сырья на выход экстрактивных веществ. Результаты приведены на рисунке.

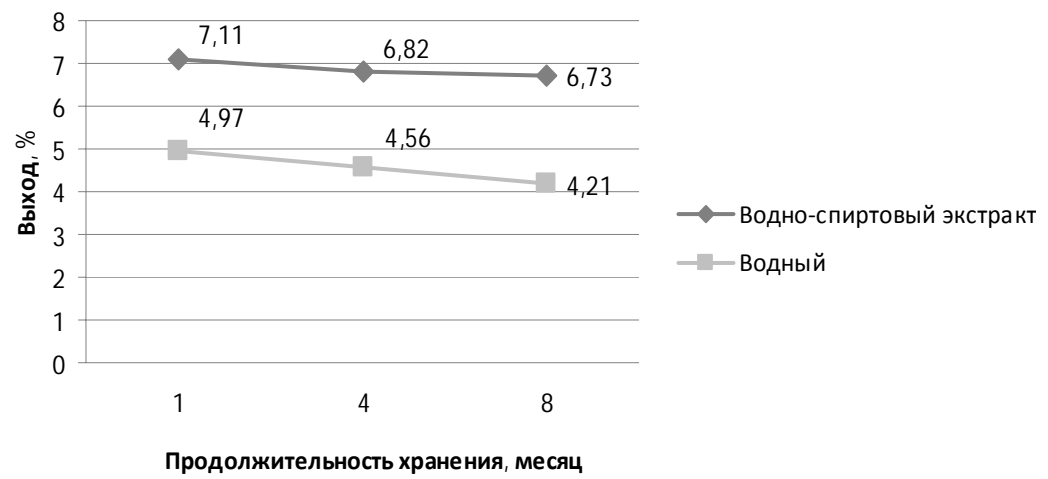
Выход экстрактивных веществ в зависимости от продолжительности хранения

Как видно из результатов, приведенных на рисунке, выход экстрактивных веществ при хранении сырья от 1 до 8 месяцев снизился, при экстракции водой на 14\%, а 45\%-м этиловым спиртом - на 4\%. Таким образом, выход экстрактивных веществ из свежего сырья, оказался более высоким, благодаря своевременному извлечению биологически активных веществ из летучих компонентов растительных тканей.

\section{Вblводbl}

Извлечение биологически активных веществ с применением 45\%-го раствора этилового спирта обеспечивает наибольший выход биологически активных веществ. Хранение сырья в течение 8 месяцев снижает выход экстрактивных веществ. При использовании в качестве экстрагента воды выход витамина С снижается - на 87,60\%, флаваноидов - на 67,80\%, витамина Р - на 63,20\%. Следовательно, для получения экстрактов с наибольшим содержанием биологически активных веществ рекомендуется использование в качестве экстрагента 45\%-го этилового спирта и свежего сырья.

\section{Список литературы}

1. Гринкевич Н.И., Баландина И.А. Лекарственные растения. М.,1991. 398 с.

2. Настойки, экстракты, эликсиры и их стандартизация : ред. В.Л. Багирова, В.А. Северцев. СПб., 2001. 223 с.

3. ГОСТ 24027.2-80. Сырье лекарственное растительное. М., 1980. С. 284-294

4. Минаева В.Г. Лекарственные растения Сибири. Новосибирск, 1991. 431 с.

5. Ушанова В.М., Лебедева О.И., Девятловская А.М. Основы научных исследований. Красноярск, 2004. 335 с.

6. Понаморев В.Г. Экстрагирование лекарственного сырья. М., 1976. 204 с. 
7. Левин Э.Д., Миронов П.В. Современные физико-химические методы исследования: методические указания к проведению лабораторных работ для студентов. Красноярск, 1988. 28 с.

8. Матвеенко Е.В., Аёшина Е.Н. Исследования экстрактивных веществ Juniperus sibirica В. // Молодые ученые в решении актуальных проблем науки : сборник статей всероссийской научно-практической конференции (с международным участием). Красноярск, 2012. Т. 1. С. 276-277.

9. Аёшина Е.Н., Величко Н.А., Экстрактивные вещества Juniperus sibirica В. // Химико-лесной комплекс - проблемы решения : материалы всероссийской конференции. Красноярск, 2004. Т. 3. С. 37-39.

10. Зырянова Ю.В., Аёшина Е.Н., Величко Н.А. Химический состав можжевельника сибирского, каллусной ткани и послеэкстрактного остатка // Химия растительного сырья. 2012. №2. С. 145-150.

Поступило в редакичию 12 февраля 2013 г.

После переработки 15 марта 2013 г.

Matveenko E.V., Aeshina E.N., Velichko N.A. COMPOSITION OF EXTRACTS GREEN WOOD JUNIPERUS SIBIRICA BURGSD

Siberian State Technological University, Mira st., 82, Krasnoyarsk, 660049 (Russia),e-mail: vollker@mail.ru

A research of influence of solvent nature is carried out on the output of biologically active substances from wood greenery Juniperus sibirica B. It is established, that the greatest output of biologically active substances from wood greenery Juniperus sibirica is observed when using the $45 \%$ ethyl alcohol. The influence of the conditions of storage on the output of extractive substances is studied.

Keywords: extract, biologically active substances, Juniperus sibirica B.

\section{References}

1. Grinkevich N.I., Balandina I.A. Lekarstvennye rasteniia. [Drug plants]. Moscow, 1991, 398 p. (in Russ.).

2. Nastoiki, ekstrakty, eliksiry $i$ ikh standartizatsiia. [Tinctures, extracts, elixirs and their standardization]. Ed. V.L. Bagirova, V.A. Severtsev St. Petersburg, 2001, 223 p. (in Russ.).

3. GOST 24027.2-80. Syr'e lekarstvennoe rastitel'noe. [State standard 24027.2-80. Raw medicinal plant]. Moscow, 1980, pp. 284-294. (in Russ.).

4. Minaeva V.G. Lekarstvennye rasteniia Sibiri. [Medicinal Plants of Siberia]. Novosibirsk, 1991, 431 p. (in Russ.).

5. Ushanova V.M., Lebedeva O.I., Deviatlovskaia A.M. Osnovy nauchnykh issledovanii. [Osnovy nauchnykh issledovanii]. Krasnoyarsk, 2004, 335 p. (in Russ.).

6. Ponamorev V.G. Ekstragirovanie lekarstvennogo syr'ia. [Extraction of crude drug]. Moscow, 1976, 204 p. (in Russ.).

7. Levin E.D., Mironov P.V. Sovremennye fiziko-khimicheskie metody issledovaniia: metodicheskie ukazaniia $k$ provedeniiu laboratornykh rabot dlia studentov. [Modern physico-chemical methods of research: guidelines for laboratory work for students]. Krasnoyarsk, 1988, 28 p. (in Russ.).

8. Matveenko E.V., Aeshina E.N. Molodye uchenye v reshenii aktual'nykh problem nauki: sbornik statei vse-rossiiskoi nauchno-prakticheskoi konferentsii (s mezhdunarodnym uchastiem). [Young scientists in solving actual problems of science: a collection of articles all-Russian scientific-practical conference (with international participation)]. Krasnoyarsk, 2012, vol. 1, pp. 276-277. (in Russ.).

9. Aeshina E.N., Velichko N.A. Khimiko-lesnoi kompleks - problemy resheniia: materialy vserossiiskoi konferentsii. [Chemical-forest complex - problem solving: a national conference materials]. Krasnoyarsk, 2004, vol. 3, pp. 37-39. (in Russ.).

10. Zyrianova Iu.V., Aeshina E.N., Velichko N.A. Khimiia rastitel'nogo syria, 2012, no. 2, pp. 145-150. (in Russ.).

Received February 12, 2013

Revised March 15, 2013

\footnotetext{
* Corresponding author.
} 
